\title{
Synergistic Reinforcement of Phenol-Formaldehyde Resin Composites by Poly(Hexanedithiol)/Graphene Oxide
}

\author{
Jingliang Wei1, Chun Wei1,2,3, Le Su${ }^{1}$, Jun Fu' ${ }^{1}$, Jian $\mathrm{Lv}^{1,2,3^{*}}$ \\ ${ }^{1}$ College of Materials Science and Engineering, Guilin University of Technology, Guilin, China \\ ${ }^{2}$ Key Laboratory of New Processing Technology for Nonferrous Metals and Materials, Ministry of Education, \\ Guilin, China \\ ${ }^{3}$ Ministry-Province Jointly-Constructed Cultivation Base for State Key Laboratory of Processing for Non-Ferrous \\ Metal and Featured Materials, Guilin, China \\ Email: ${ }^{\text {1986024@glut. edu.cn }}$
}

Received 1 June 2015; accepted 10 August 2015; published 13 August 2015

Copyright (C) 2015 by authors and Scientific Research Publishing Inc.

This work is licensed under the Creative Commons Attribution International License (CC BY). http://creativecommons.org/licenses/by/4.0/

(c) (7) Open Access

\section{Abstract}

In this paper, the preparation of graphene oxide was achieved by Hummers method and the surface modification was achieved by poly(hexaneditiol), which was a synthetic thermotropic liquid crystalline polymer. The c-PHDT/GO/PF composites were prepared by blending, rolling and compression molding techniques. Then, the as-prepared samples were characterized by FTIR, Raman, XRD, TGA and POM to obtain information on their structures and properties. After that, the effects of c-PHDT/GO content on the mechanical properties, friction performance and dynamic mechanical performance of c-PHDT/GO/PF composites were studied by Mechanical and Dynamic Mechanical Analysis (DMA) methods. Also, Scanning Electron Microscope (SEM) was used for the characterization of wear and fracture surface morphology. The results revealed that the reinforcing effect of c-PHDT/GO was significant as a considerable enhancement on the mechanical performance of c-PHDT/GO/PF composite as compared to pure phenol-formaldehyde composites was observed: the impact strength, bending modulus and bending strength increased from $1.63 \mathrm{~kJ} / \mathrm{m}^{2}, 8.61 \mathrm{GPa}$ and $41.55 \mathrm{MPa}$ to $2.31 \mathrm{~kJ} / \mathrm{m}^{2}, 10.16 \mathrm{GPa}$ and $54.40 \mathrm{MPa}$ respectively at the $\mathrm{c}-\mathrm{PHDT} / \mathrm{GO}$ content = $0.75 \%$. Moreover, the initial storage modulus increased by $\mathbf{2 8 . 4 \%}$, while the wear mass loss decreased by $17.8 \%$. More importantly, the reinforcement by c-PHDT/GO was further enhanced as compared to GO/PF and p-PHDT/GO/PF composites, the impact strength of c-PHDT/GO/PF composite increased by $27.6 \%$ and $11.1 \%$, the bending strength increased by $11.8 \%$ and $7.6 \%$, the initial storage modulus increased by $16.2 \%$ and $4.2 \%$ and the mass loss due to wear decreased by $12.7 \%$ and $8.8 \%$, respectively. Based on these results, we can conclude that the surface modification of GO by poly(hexanedithiol), which includes synergistic effect by c-PHDT and GO, improves the interfacial adhesion between $\mathrm{GO}$ and the resin matrix, thus reinforcing the composites.

*Corresponding author.

How to cite this paper: Wei, J.L., Wei, C., Su, L., Fu, J. and Lv, J. (2015) Synergistic Reinforcement of Phenol-Formaldehyde Resin Composites by Poly(Hexanedithiol)/Graphene Oxide. Journal of Materials Science and Chemical Engineering, 3, 56-70. http://dx.doi.org/10.4236/msce.2015.38009 


\section{Keywords}

\section{Poly(Hexanedithiol), Graphene Oxide, Phenol Formaldehyde Resin, Mechanical Properties}

\section{Introduction}

Graphene is a carbon nanometer material comprising a single and tightly packed 2D layer of sp $^{2}$-hybridized carbon atoms that are bonded together in a hexagonal honeycomb lattice [1]. With the minimum thickness (one atom thick, namely $0.355 \mathrm{nM}$ ) currently reported for 2D materials, this unique 2D crystal has shown various advantages such as excellent electrical [2] and mechanical [3] properties, ultra-large surface, low friction coefficient [4] and tunneling effect. Therefore, graphene has been a popular research topic globally in the past few years.

One of the key research areas for this material is the graphene-based nanocomposites including graphene/polymer nanocomposites [5]-[8] and graphene/inorganic nanocomposites [9]. For instance, the fabrication of graphene/epoxy resin nanocomposites by reduction of graphene oxide [10], the composition of modified graphene, single-walled carbon nanotubes and expanded graphite by solution dispersion method in PMMA [10], graphene/ foamed organic silicon nanocomposites, graphene/polymer conductive nanocomposites, graphene oxide/polymer nanocomposites as lubricants for coatings, etc. [11] [12]. It has been proved that the graphene/polymer composites can be significantly enhanced in terms of mechanical, thermal and electrical properties as compared to the conventional polymers. For instance, $1.0 \mathrm{wt} \%$ of graphene [8] leads to a $40^{\circ} \mathrm{C}$ increase in the glass transition temperature of PAN and $0.01 \mathrm{wt} \%$ of graphene [13] leads to a $33 \%$ increase in the elastic modulus of PMMA.

Phenol-formaldehyde resin (PF) is a thermoset resin that has been widely applied in virtue of their excellent properties such as high strength, excellent thermostability and electrical insulation, and good dimensional stability. Also, this material presents intrinsic advantages of resins such as flame retardance, ablation resistance and low smoke yield ratio [14] [15]. Nevertheless, some other intrinsic properties of this material have limited its application in various fields. For example, the resin matrix is relatively brittle due to the closely packed rigid aromatic rings, which are attached to the methylene groups. Also, the thermostability and oxidation resistance are relatively weak due to the presence of phenolic hydroxyl and methylene groups [16] [17]. For this reason, the strengthening and toughening of PF is a hot topic in the field of composite materials.

Liquid crystalline polymers are those polymers that are in the phase of liquid crystal under certain conditions. In virtue of the combination of high molecular weight and liquid crystalline phase sequence, this material shows unique mechanical and other physical properties [18] [19]. In the melting process, the rigid macromolecules are highly oriented in terms of flow direction and the hardening effect was retained after curing. In virtue of its excellent self-reinforcement, heat resistance and high modulus, this material has been intensively studied for the in-situ reinforcement of composites [20] [21].

Based on studies reported [22]-[25], we present the fabrication of graphene oxide by modified Hummers method, followed by surface modification by synthetic PHDT to obtain modified graphene oxide (c-PHDT/GO). With blending, rolling and compression molding, the c-PHDT/GO/PF composite was prepared and the synergistic effect of c-PHDT/GO on the mechanical properties, friction performance and dynamic mechanical performance was investigated. In this way, this study serves as a reference for further studies of the synergistic reinforcement of PF by c-PHDT/GO.

\section{Experimental}

\subsection{Raw Materials}

The graphene oxide (GO) was prepared by modified Hummers method as reported previously [26] [27]. The poly (hexaneditiol) (PHDT) with a melting point of $160^{\circ} \mathrm{C}$ and a clearing point of $236^{\circ} \mathrm{C}$ was prepared by a method reported previously [28]. The phenol-formaldehyde resin, thionyl chloride (analytical grade), N, N-Dimethyl formamide (analytical grade) and pyridine (analytical grade) were purchased from Shengquan Chemical Corporation, Jinhuada Pte Ltd. and Xilong Chemical Corporation respectively. 


\subsection{Fabrication of Modified Graphene Oxide}

Firstly, 200 g graphene oxide was weighed and added into a $250 \mathrm{ml}$ three-neck flask with reflux condenser, thermometer and magneton, followed by addition of $50 \mathrm{ml}$ thionyl chloride and $2 \mathrm{ml}$ DMF. Then, the reflux reaction at $75^{\circ} \mathrm{C}$ for $24 \mathrm{~h}$ was allowed, followed by removal of residual thionyl chloride by distillation under reduced pressure. In this way, the thionyl chlorinated graphene oxide was obtained [29]. In the next step, $4 \mathrm{~g}$ PHDT, $50 \mathrm{ml}$ DMF and a certain quantity of pyridine were added into the flask with thionyl chlorinated graphene oxide and the flask was kept at $95^{\circ} \mathrm{C}-100^{\circ} \mathrm{C}$ for $24 \mathrm{~h}$. Afterwards, the mixture solution was rinsed by DI water and ethanol and filtered for 4 times. The product was dried in vacuum oven at $80^{\circ} \mathrm{C}$ for $24 \mathrm{~h}$ to obtain c-PHDT/GO. On the other hand, graphene oxide without treatment by thionyl chloride was mixed with liquid crystal to obtain physically blended p-PHDT/GO as a control group. The modification of graphene oxide was done as shown in Figure 1.

\subsection{Fabrication of PF Composites}

Firstly, GO, c-PHDT/GO and p-PHDT/GO were mixed and extruded at $140^{\circ} \mathrm{C}$ by YBY-I micro-scale mixingextruding integrated experimental device. Then, the extruded product was crumbled, followed by addition of curing agents and fillers according to suggested ratio. Afterwards, rolling of the mixture was conducted, followed by second crumbling and compression molding to obtain the composite samples. The parameters of compression molding were as follow: $160^{\circ} \mathrm{C}-170^{\circ} \mathrm{C}, 10 \mathrm{MPa}$ and $5 \mathrm{~min}$. Once cooled down, post-curing $\left(120^{\circ} \mathrm{C}\right.$ for $2 \mathrm{~h}+140^{\circ} \mathrm{C}$ for $2 \mathrm{~h}+160^{\circ} \mathrm{C}$ for $2 \mathrm{~h}+180^{\circ} \mathrm{C}$ for $2 \mathrm{~h}$ ) were applied to the samples and GO/PF, c-PHDT/GO/PF and p-PHDT/GO/PF composites were obtained. Figure 2 shows the preparation process of PF composites.

\subsection{Characterization and Testing}

Fourier transform infrared (FTIR) spectra were measured on a Thermo Nexus 470 FTIR spectrometer (KBr disk). Raman spectra were recorded on a Thermo Fisher Scientific DXR Raman spectroscopy. Thermogravimetric analysis (TGA) were carried out on a TA Q500 instrument with a heating rate of $10^{\circ} \mathrm{C} / \mathrm{min}$ in a $\mathrm{N}_{2}$ flow. Powder X-ray diffraction (XRD) spectra were taken on a Holland PAN alytical X-Pert PRO X-ray diffractometer with $\mathrm{Cu} \mathrm{K} \alpha$ radiation. Dynamic thermomechanical analysis (DMA) were performed on a TA DMA-Q800 instrument, sample size was $40 \mathrm{~mm} \times 10 \mathrm{~mm} \times 4 \mathrm{~mm}$ with a heating rate of $3^{\circ} \mathrm{C} / \mathrm{min}$ from $50^{\circ} \mathrm{C}$ to $300^{\circ} \mathrm{C}$. Liquid crystalline texture were examined using a XPN-203 polarized optical microscopy (POM) equipped with a hot stage. Sharpy impact tests were performed on the XJJ-5 tester, the specimens were rectangular bars with dimen-

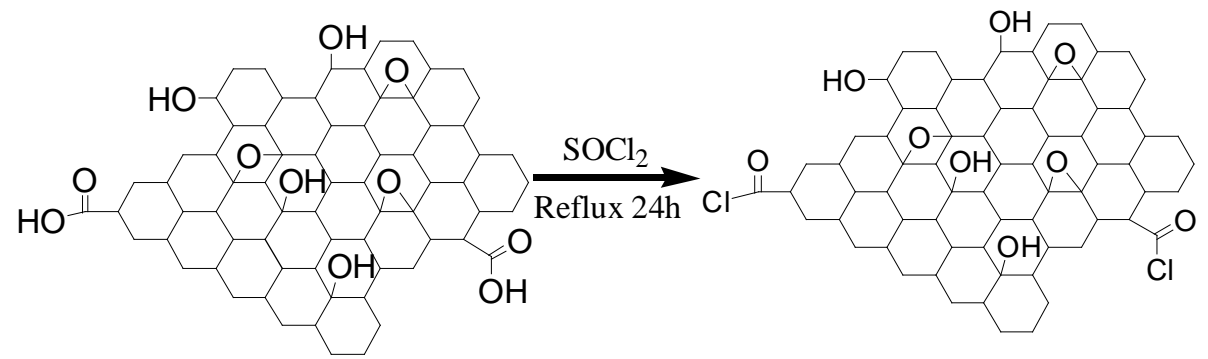

Figure 1. The modification of graphene oxide.

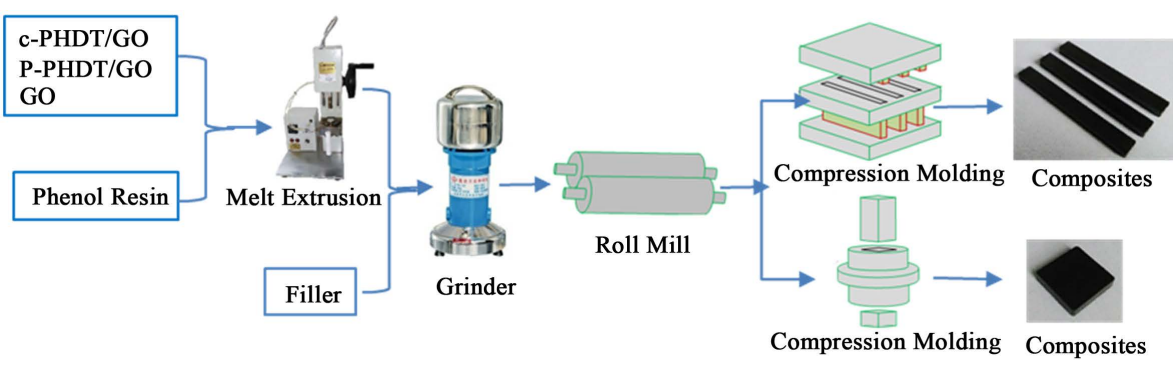

Figure 2. Preparation process of PF composites. 
sions of $4 \times 10 \times 120 \mathrm{~mm}$, in accordance with the National standards GB1043-93. At least five specimens were tested and their average value was taken. Three-point bending tests were performed on AG-201 computer controlled electronic universal testing machine at a pressing speed of $2 \mathrm{~mm} / \mathrm{min}$ and a gauge length of $64 \mathrm{~mm}$ in accordance with the National standards GB9341-2000. The sample size was $4 \times 10 \times 120 \mathrm{~mm}$. At least five specimens were tested and their average value was taken. The friction tests were conducted on a constant speed (D-SM) tester. The friction disk is made of cast iron (HT250) with a hardness of 210 HB. The tester offers a friction temperature range of $100^{\circ} \mathrm{C}-300^{\circ} \mathrm{C}$, which is automatically adjusted. The load was $0.98 \mathrm{MPa}$ on each slider and the speeds were in the interval of $480 \mathrm{r} / \mathrm{min}$. The friction tests were carried out at $100^{\circ} \mathrm{C}, 150^{\circ} \mathrm{C}$, $200^{\circ} \mathrm{C}, 250^{\circ} \mathrm{C}, 300^{\circ} \mathrm{C}$ and each test lasted for $10 \mathrm{~min}$, in accordance with the standards GB 5763-2008. The Vickers hardness test was conducted on the MH-6microhardness tester. The density tests were conducted on the AND-300d tester. At least three specimens were tested and their average value was taken. A JSM-6380 LV scanning electron microscope (SEM) was used to observed the morphology of worn and fracture surfaces which were sputtered a thin layer of gold.

\section{Results and Discussions}

\subsection{Characterization of Modified Graphene Oxide}

\subsubsection{Infra-Red Characterization}

Figures 3(a)-(c) show the IR spectra of c-PHDT, p-PHDT and PHDT respectively. According to these figures, similar absorption peaks were observed for the three samples: peak at $3410 \mathrm{~cm}^{-1}$ due to hydroxyl group, absorption peaks at $2950 \mathrm{~cm}^{-1}$ and $2840 \mathrm{~cm}^{-1}$ due to methylene group, peak at $1730 \mathrm{~cm}^{-1}$ due to stretching vibration of $\mathrm{C}=\mathrm{O}$ bond, peaks at $1600 \mathrm{~cm}^{-1}$ and $1500 \mathrm{~cm}^{-1}$ due to stretching vibration of aromatic benzene rings and peaks at $1270 \mathrm{~cm}^{-1}$ and $1070 \mathrm{~cm}^{-1}$ due to stretching vibration of C-O bond.

As shown in Figure 3(d), absorption peaks at $3400 \mathrm{~cm}^{-1}$ and $1627 \mathrm{~cm}^{-1}$ are believed to be a result of hydroxyl groups and adsorbed moisture in GO, absorption peak at $1723 \mathrm{~cm}^{-1}$ is due to $\mathrm{C}=\mathrm{O}$ bond, peaks at $1384 \mathrm{~cm}^{-1}$ and $1050 \mathrm{~cm}^{-1}$ are due to bending vibration of C-O bond and stretching vibration of C-O-C group respectively. By comparison, it is concluded that the similar IR spectra of c-PHDT, p-PHDT and PHDT are due to the similar oxygen-containing functional groups in GO and PHDT.

\subsubsection{Raman Characterization}

The Raman spectra of graphite, graphene oxide, c-PHDT/GO and p-PHDT/GO are shown in Figure 4. According to Figure 4(a), a strong $G$ peak at $1582 \mathrm{~cm}^{-1}$ and a weak D peak at $1351 \mathrm{~cm}^{-1}$ and are observed in the spectrum of graphite. These peaks are due to the $\mathrm{sp}^{2}$ and $\mathrm{sp}^{3}$ hybridized carbon atoms respectively. The presence of

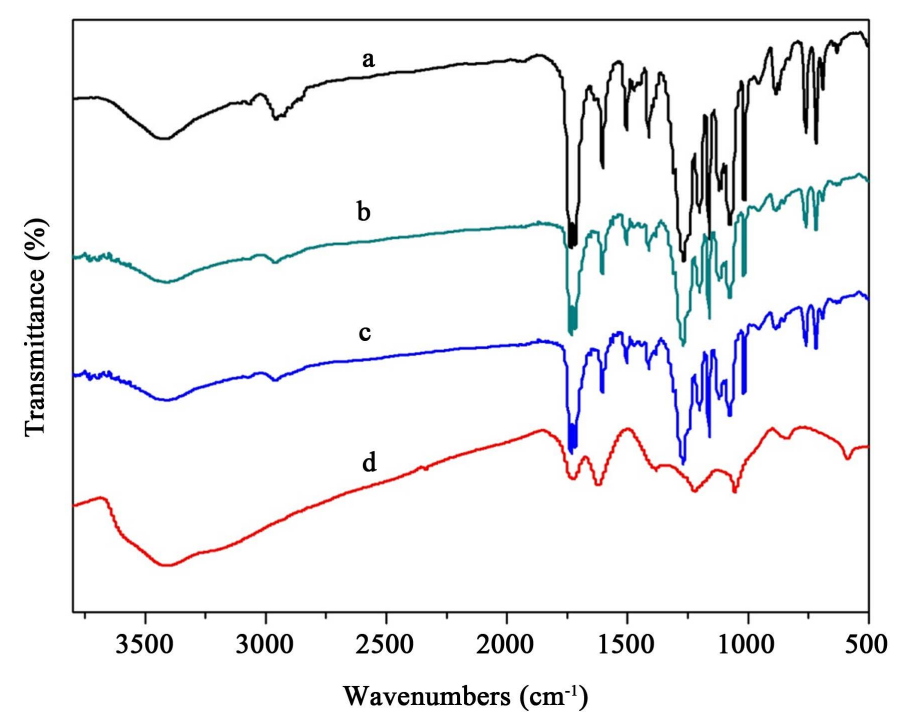

Figure 3. Infrared spectrum of (a) c-PHDT/GO; (b) p-PHDT/GO; (c) PHDT and (d) GO. 


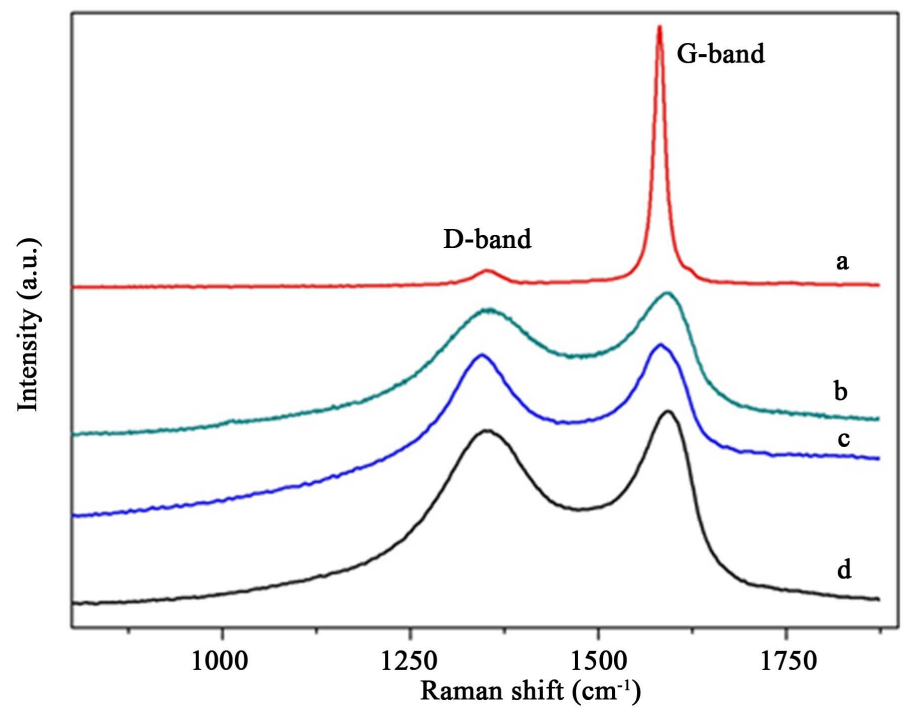

Figure 4. The Raman spectra of (a) Graphite; (b) GO; (c) c-PHDT/GO and (d) p-PHDT/GO.

the $\mathrm{D}$ peak at $1351 \mathrm{~cm}^{-1}$ indicated the transformation from $\mathrm{sp}^{2}$ hybridization to $\mathrm{sp} 3$ hybridization and the peak intensity is positively related to the content of $\mathrm{sp}^{3}$ hybridized atoms. As shown in Figure 4(b), the structure of $\mathrm{GO}$ is different from that of graphite. For instance, two strong peaks were observed at $1582 \mathrm{~cm}^{-1}$ and $1351 \mathrm{~cm}^{-1}$ respectively and the intensity ratio between D peak and G peak (ID/IG) was 0.96 . The intensity increase of D peak resulted from oxidation process, which promoted and accelerated the transformation from $\mathrm{sp}^{2}$ to $\mathrm{sp}^{3}$ hybridization. According to Figure 4(c) and Figure 4(d), the peaks in the spectra of c-PHDT/GO and p-PHDT/GO are similar to those in the spectrum of GO. The peak positions were $1583 \mathrm{~cm}^{-1}$ and $1345 \mathrm{~cm}^{-1}$ in c-PHDT/GO spectrum and $1593 \mathrm{~cm}^{-1}$ and $1352 \mathrm{~cm}^{-1}$ in p-PHDT/GO spectrum. Meanwhile, red shift phenomenon was observed in the spectrum of c-PHDT/GO, indicating the presence of $\pi-\pi^{*}$ conjugation in the system. In addition, the ID/IG in c-PHDT/GO and p-PHDT/GO were 0.97 and 0.90 respectively.

\subsubsection{X-Ray Diffraction Characterization}

According to Table 1 and Figure 5, graphite showed a diffraction peak at $2 \theta=26.55^{\circ}$ and GO showed one at $2 \theta$ $=11.42^{\circ}$. The diffraction peak at $2 \theta=11.42^{\circ}$ in GO was a result of agglomeration. In the spectra of PHDT, c-PHDT/GO and p-PHDT/GO, strong peaks were observed in the range of $2 \theta=19^{\circ}$ and $2 \theta=23^{\circ}$, indicating the presence of crystals in all of the three samples, besides the amorphous components. In addition, a diffraction peak at $2 \theta=21.05^{\circ}$ was observed in the spectrum of c-PHDT/GO, indicating that the structure of this sample was affected by the surface modification.

\subsubsection{Thermogravimetric Analysis}

The TGA results of PHDT, c-PHDT/GO, p-PHDT/GO and GO are shown in Figure 6, Figure 7 and Table 2. According to Figure 6 and Figure 7, a rapid decomposition was observed in GO at temperature lower than $250^{\circ} \mathrm{C}$. The corresponding temperature of highest decomposition rate was $223^{\circ} \mathrm{C}$. This can be explained by the presence of oxygen-containing functional groups, which can be easily detached. At $\mathrm{T}>250^{\circ} \mathrm{C}$, these functional groups had been completely removed and the decomposition process was significantly decelerated. At $\mathrm{T}=$ $700^{\circ} \mathrm{C}$, the carbon yield of GO was $40 \%$. As shown in the figure, the decomposition temperature at $5 \%$ mass loss ( $\mathrm{T}_{\mathrm{d}} 5 \%$ ) for c-PHDT/GO was $348^{\circ} \mathrm{C}$, which was increased by $18^{\circ} \mathrm{C}, 51^{\circ} \mathrm{C}$ and $214^{\circ} \mathrm{C}$ as compared to PHDT, p-PHDT /GO and GO respectively. At T $=700^{\circ} \mathrm{C}$, the carbon yield of c-PHDT/GO was $22.9 \%$, which was increased by $3.56 \%$ and $5.46 \%$ as compared to PHDT and p-PHDT /GO respectively. Meanwhile, the temperature of initial decomposition was $357^{\circ} \mathrm{C}$. By comparing c-PHDT/GO and p-PHDT/GO, we can conclude that the thermal behavior of c-PHDT/GO was significantly enhanced, indicating the formation of covalent bonds between PHDT and oxygen-containing functional groups on GO as a result of surface modification. In addition, the $\pi-\pi^{*}$ conjugation between PHDT and GO plays a key role in the enhancement of thermal behaviors well. 


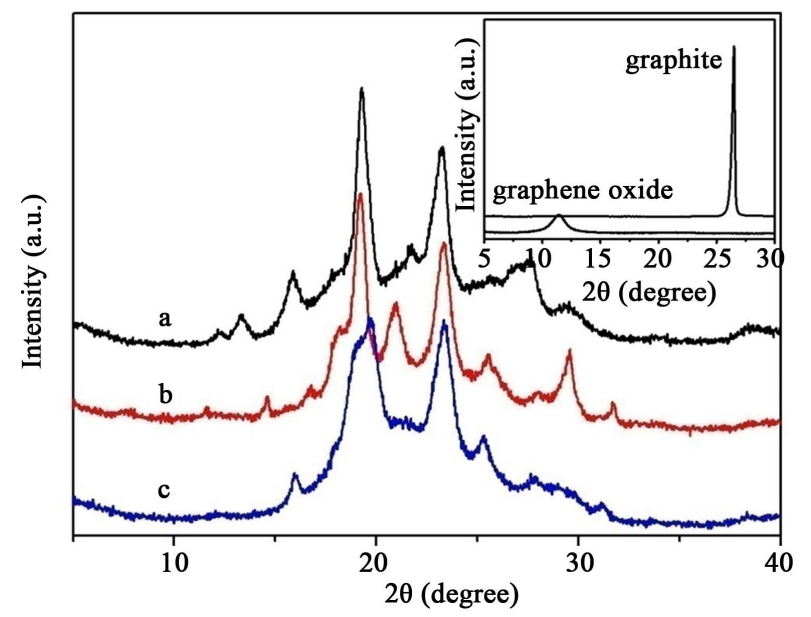

Figure 5. WAXD results of PHDT, c-PHDT/GO, p-PHDT/GO, GO and Graphite.

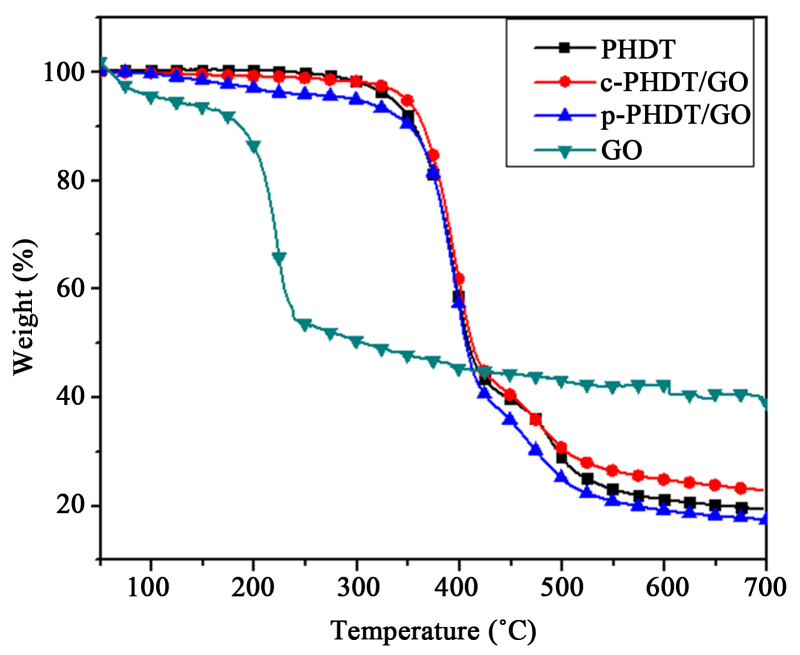

Figure 6. TGA curve of PHDT, c-PHDT/GO, p-PHDT/GO and GO.

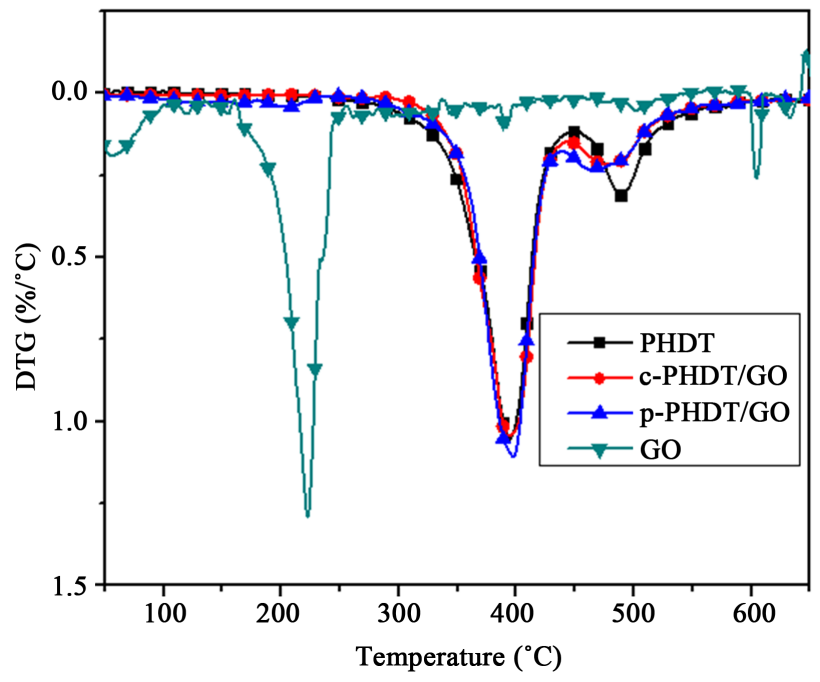

Figure 7. DTG curve of PHDT, c-PHDT/GO, p-PHDT/GO and GO. 
Table 1. WAXD results of PHDT, c-PHDT/GO, p-PHDT/GO, GO and graphite.

\begin{tabular}{cccccccccc}
\hline Samples & $2 \theta\left(^{\circ}\right)$ & $\mathrm{d}(\AA)$ & $2 \theta\left(^{\circ}\right)$ & $\mathrm{d}(\AA)$ & $2 \theta\left(^{\circ}\right)$ & $\mathrm{d}(\AA)$ & $2 \theta\left(^{\circ}\right)$ & $\mathrm{d}(\AA)$ \\
\hline PHDT & 15.85 & 5.59 & 19.29 & 4.6 & 23.31 & 3.82 & 27.75 & 3.21 \\
c-PHDT/GO & 19.3 & 4.6 & 21.05 & 4.11 & 23.33 & 3.81 & 29.58 & 3.02 \\
p-PHDT-GO & 15.99 & 5.54 & 19.74 & 4.5 & 13.4 & 3.8 & 25.31 & 3.52 \\
GO & 11.42 & 7.66 & - & - & - & - & - & - \\
Graphite & - & - & - & - & 26.55 & 3.36 & - & - \\
\hline
\end{tabular}

Table 2. Thermal analysis results of PHDT, c-PHDT/GO, p-PHDT/GO and GO.

\begin{tabular}{ccccccc}
\hline Samples & $\mathrm{T}_{\text {onset }}\left({ }^{\circ} \mathrm{C}\right)$ & $\mathrm{T}_{\mathrm{d} 5 \%}\left({ }^{\circ} \mathrm{C}\right)$ & $\mathrm{T}_{\mathrm{d} 15 \%}\left({ }^{\circ} \mathrm{C}\right)$ & $\mathrm{T}_{\mathrm{d} 60 \%}\left({ }^{\circ} \mathrm{C}\right)$ & Residual Mass\% $\left(700^{\circ} \mathrm{C}\right)$ & $\mathrm{V}_{\max }\left({ }^{\circ} \mathrm{C}\right)$ \\
\hline PHDT & 340 & 329 & 363 & 447 & 19.4 & 394 \\
c-PHDT/GO & 357 & 348 & 374 & 453 & 22.9 & 392 \\
P-PHDT-GO & 212 & 297 & 368 & 427 & 17.5 & 397 \\
GO & 180 & 114 & 203 & 698 & 40 & 223 \\
\hline
\end{tabular}

$\mathrm{T}_{\text {onset }}$ correspond to starting decomposition temperature. $\mathrm{T}_{\mathrm{d} 5 \%}, \mathrm{~T}_{\mathrm{d} 15 \%}, \mathrm{~T}_{\mathrm{d} 60 \%}$ correspond to decomposition temperature of $5 \%, 15 \%$ and $60 \%$ weight loss, respectively.

\subsubsection{Characterization by Polarizing Optical Microscope (POM)}

Figure 8 shows the POM images of PHDT, c-PHDT/GO, p-PHDT/GO. The heating process started from room temperature. Below melting temperatures, a dark view was observed. Once the meting process initiated, colour strips occurred and expanded as the heating continued. At $\mathrm{T}=$ clearing point, the color stripes disappeared and the view returned to dark. Figure 8(a) and Figure 8(b) show the polarizing images of PHDT. As we can see, colored threaded structure was observed and the liquid crystalline range of PHDT was $164^{\circ} \mathrm{C}-240^{\circ} \mathrm{C}$. Figure 8(c) and Figure 8(d) show the images of c-PHDT/GO and p-PHDT/GO at temperature higher than their respective melting temperature. A dark region and a clear region were observed in this image. The clear region was a result of the birefringence phenomenon in the melting process of liquid crystals while the dark region was resulted from GO. In c-PHDT/GO and p-PHDT/GO, the birefringence was attenuated, indicating that the presence of GO had an effect on the liquid crystalline structure.

\subsection{Mechanical Properties of G0/PF Composites}

\subsubsection{Effect of GO Surface Modification on the Mechanical Properties of GO/PF Composites}

Table 3 shows the mechanical properties of the as-prepared GO/PF composite samples. As we can see, the impact strength, bending modulus and bending strength of all the three samples surpassed those of pure PF sample. In addition, the impact strength of c-PHDT/GO/PF composite increased by $27.6 \%$ and $11.1 \%$, the bending strength increased by $11.8 \%$ and $7.6 \%$, as compared to GO/PF and p-PHDT/GO/PF respectively. As a result, it is concluded that the mechanical performance of GO/PF composites can be enhanced by surface modification in GO. A possible mechanism of the enhancement is that the interfacial compatibility between PF and GO was improved as a result of the surface modification on GO by PHDT and the synergistic effect of GO and PHDT on the composites.

\subsubsection{Effect of GO Surface Modification on the Friction Performance of GO/PF Composite}

Figure 9 and Table 4 show the friction performance of the as-prepared GO/PF composite samples. The results revealed that the wear mass loss of PF composites increased with increasing temperature, while the mass loss of pure PF composite was the highest one. This served as a proof that the involvement of GO, p-PHDT/GO and cPHDT/GO can enhance the wear resistance of the composite and c-PHDT/GO is the most effective one. The mass loss of c-PHDT/GO/PF decreased by $17.5 \%, 12.7 \%$ and $8.8 \%$, as compared to pure $\mathrm{PF}, \mathrm{GO} / \mathrm{PF}$ and pPHDT/GO/PF composites respectively. In the wear process, the thermal decomposition of the stratified GO led 


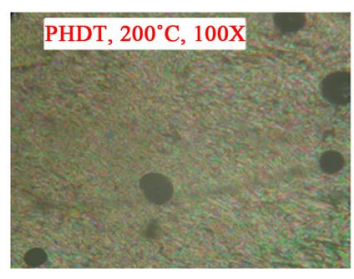

(a)

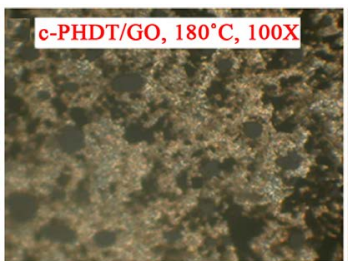

(c)

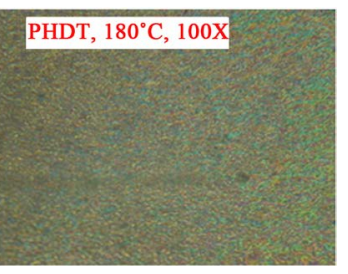

(b)

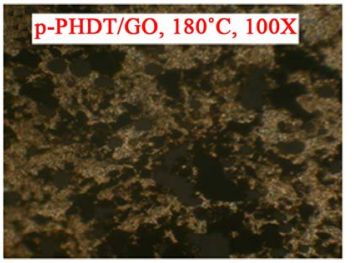

(d)

Figure 8. The POM images of PHDT, c-PHDT/GO and pPHDT/GO.

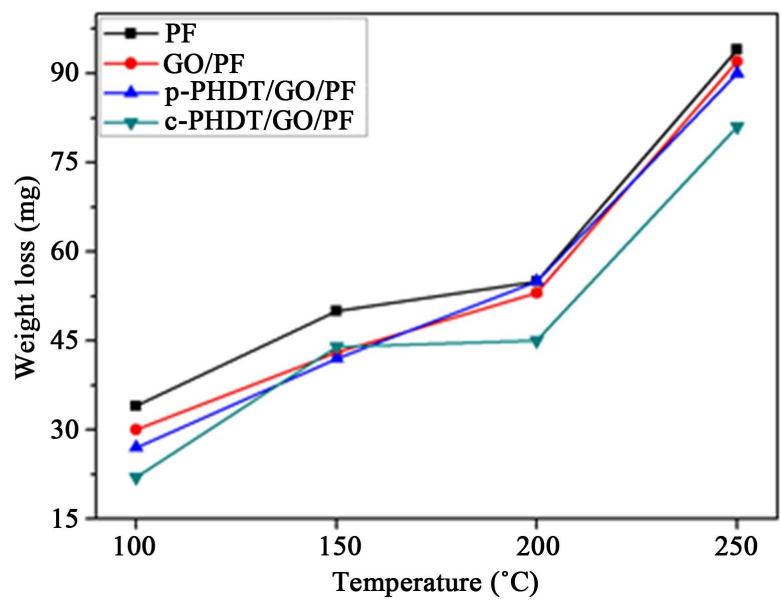

Figure 9. The effects of modified GO on wear mass loss of PF composites.

Table 3. Effects of modified GO on the mechanical properties of the PF composites.

\begin{tabular}{cccc}
\hline Samples & Impact strength $\left(\mathrm{KJ} / \mathrm{m}^{2}\right)$ & Flexural modulus $(\mathrm{GPa})$ & Flexural strength $(\mathrm{MPa})$ \\
\hline $\mathrm{PF}$ & 1.63 & 8.61 & 41.55 \\
$\mathrm{GO} / \mathrm{PF}$ & 1.81 & 9.82 & 48.65 \\
p-PHDT/GO & 2.08 & 10.05 & 50.54 \\
c-PHDT/GO & 2.31 & 10.16 & 54.38 \\
\hline
\end{tabular}

Table 4. Effects of modified GO on wear property of PF composites.

\begin{tabular}{|c|c|c|c|c|c|c|}
\hline Samples & $\mathrm{M}_{100}(\mathrm{mg})$ & $\mathrm{M}_{150}(\mathrm{mg})$ & $\mathrm{M}_{200}(\mathrm{mg})$ & $\mathrm{M}_{250}(\mathrm{mg})$ & $\mathrm{M}_{\mathrm{R}}(\mathrm{mg})$ & $\mathrm{M}_{\mathrm{S}}(\mathrm{mg})$ \\
\hline $\mathrm{PF}$ & 34 & 50 & 55 & 94 & 42 & 275 \\
\hline $\mathrm{GO} / \mathrm{PF}$ & 30 & 43 & 53 & 92 & 42 & 260 \\
\hline p-PHDT/GO & 27 & 42 & 55 & 90 & 40 & 249 \\
\hline с-PHDT/GO & 22 & 44 & 45 & 81 & 34 & 227 \\
\hline
\end{tabular}

M100-250, MR, and MS correspond to mass loss of the composites at different temperature, recovery and whole Friction process, respectively. 
to the formation of a carbon film transfer layer, which served as lubricant between the composite and the friction surface. The modified GO enhanced the compatibility of the reinforcing components and polymer, thus the interfacial effect of the composite. For this reason, the wear mass loss of c-PHDT/GO/PF was minimized.

As shown in Figure 10, the presence of GO and PHDT can enhance the Vickers hardness of the composite. Additionally, the hardness enhancement was maximized in the c-PHDT/GO/PF composite, indicating that the modified GO can enhance the interfacial adhesion. The composite hardness is inversely proportional to the wear mass loss, while the composite density was not significantly affected by GO.

Figure 11 shows SEM images of the abrasive surfaces of the samples. As shown in Figure 11(a) and Figure 11(b), a large quantity of furrows and severe filler exfoliation were observed on the abrasive surface. In addition, severe thermal degradation was observed in the friction test. According to Figure 11(c) and Figure 11(d), the abrasive surfaces were smooth and the quantity and depth of furrows and filler exfoliation were significantly reduced, indicating that the wear resistance of the composites were significantly improved by p-PHDT/GO and c-PHDT/GO.

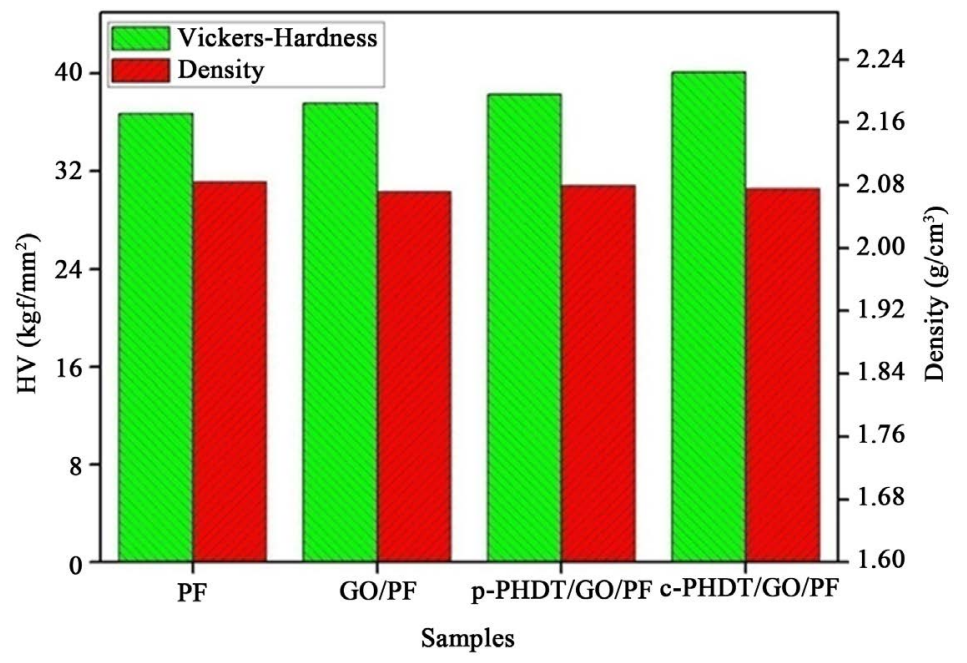

Figure 10. The vickers-hardness and density of friction samples.

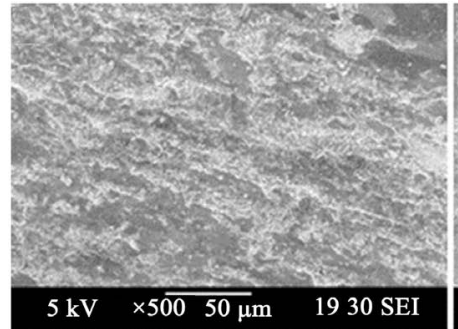

(a)

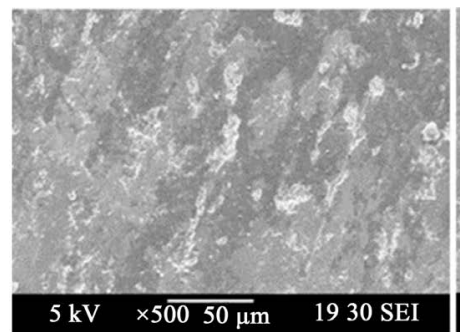

(c)

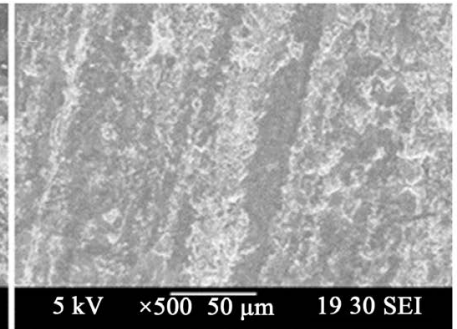

(b)

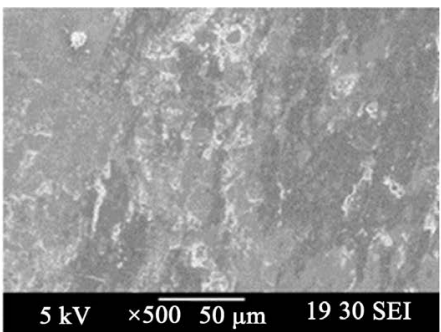

(d)

Figure 11. The SEM images of worn surface of PF composites. (a) PF; (b) GO/ PF; (c) p-PHDT/GO/PF; (d) c-PHD/GO/PF. 


\subsection{DMA Results of G0/PF Composites}

Figure 12 shows the storage modulus (E') and loss factor curves of the four composite samples. The relevant data was shown in Table 5. According to Figure 12, at $\mathrm{T}<\mathrm{T}_{\mathrm{g}}$, the storage modulus of GO/PF, p-PHDT/GO/PF and c-PHDT/GO/PF samples were higher than that of pure PF sample. Among the four samples, the c-PHDT/ GO/PF sample showed the highest storage modulus. For instance, the storage modulus of c-PHDT/GO/PF sample was $7384 \mathrm{MPa}$ at $50^{\circ} \mathrm{C}$, which is $26.2 \%, 16.2 \%$ and $4.2 \%$ higher than the modulus of PF, GO/PF and p$\mathrm{PHDT} / \mathrm{GO} / \mathrm{PF}$ respectively. Although the modulus of all the samples decreased with increasing temperature, the modulus of c-PHDT/GO/PF was still highest $(5904 \mathrm{MPa})$ at $100^{\circ} \mathrm{C}$. In addition, the storage modulus of c-PHDT/ $\mathrm{GO} / \mathrm{PF}$ sample was never lower than that of pure PF sample in the whole process. This can be explained by the synergistic reinforcement as a result of the PHDT modified GO, which can improve the interfacial adhesion and rigidity of the composite.

According to Figure 13 and Table 5, the $\mathrm{T}_{\mathrm{g}}$ of p-PHDT/GO/PF and c-PHDT/GO/PF samples was $8^{\circ} \mathrm{C}$ lower than that of pure PF sample. A possible reason is the presence of PHDT, whose melting temperature and clearing point are relatively low. In the case that the sample was at the state of liquid crystal, the freedom of motion of the chains increased, resulting in a lower glass transition temperature.

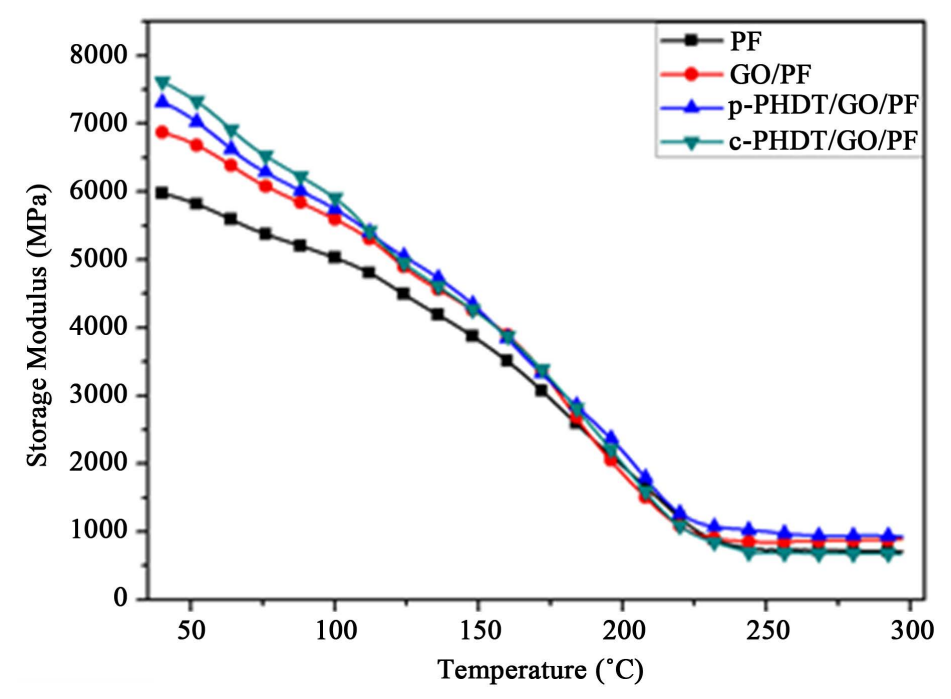

Figure 12. Effects of modified GO on storage modulus of PF composites.

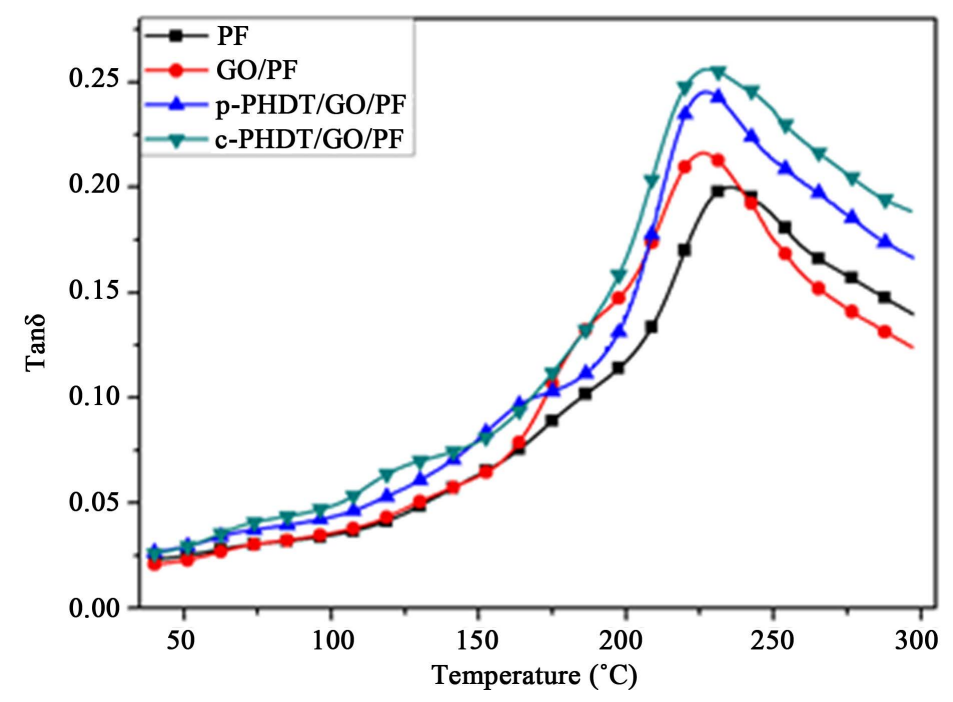

Figure 13. Effects of modified graphene oxide on Tan $\delta$ of PF composites. 
Table 5. Dynamical mechanical properties of PF composites.

\begin{tabular}{cccccc}
\hline Samples & E'$_{50}(\mathrm{MPa})$ & $\mathrm{E}^{\prime}{ }_{100}(\mathrm{MPa})$ & $\mathrm{E}_{150}^{\prime}(\mathrm{MPa})$ & $\mathrm{E}^{\prime}{ }_{200}(\mathrm{MPa})$ & $\mathrm{Tg}\left({ }^{\circ} \mathrm{C}\right)$ \\
$\mathrm{PF}$ & 5845 & 5027 & 3813 & 1968 & 234 \\
GO/PF & 6719 & 5597 & 4202 & 1858 & 225 \\
p-PHDT/GO/PF & 7081 & 5745 & 4260 & 2189 & 227 \\
c-PHDT/GO/PF & 7379 & 5904 & 4206 & 2005 & 228 \\
\hline
\end{tabular}

\subsection{Effect of c-PHDT/GO Content on the Properties of Composites}

\subsubsection{Effect on the Mechanical Properties of Composites}

Table 6 shows the effect on c-PHDT/GO content on the mechanical properties of composites. According to this table, the impact strength, bending modulus and bending strength were enhanced by the presence of c-PHDT/ GO. As the content increased, the mechanical performance of the sample increased and then decreased. With a content of $0.75 \%$, the impact strength, bending modulus and bending strength were $2.31 \mathrm{~kJ} / \mathrm{m}^{2}, 10.16 \mathrm{GPa}$ and 54.40 MPa respectively. This can be explained by the presence of modified GO, which is hydrophobic and can be readily dispersed in the PF. Meanwhile, the self-enhancing liquid crystalline polymer has a similar structure with that of PF and can enhance the interfacial effect between GO and PF, thus the mechanical performance of the composite. The degradation of mechanical performance was believed to be a result of non-uniform distribution of modified GO in the PF matrix. Due to the agglomeration of GO, internal focal points of stress were formed, resulting in degraded mechanical properties of the sample.

\subsubsection{Effect on the Friction Performance of Composites}

Figure 14 and Table 7 show the effect of c-PHDT/GO content on friction performance of composites. As we can see, the wear mass loss of sample increased with increasing temperature, while the loss was reduced in all of the GO/PF samples at different temperatures as compared to the pure PF sample. With c-PHDT/GO content to be $0.5 \%$ and $0.75 \%$, the wear mass loss was minimized (17.8\% lower than that of pure PF sample). This can be explained by the reduced content of oxygen-containing functional groups in modified GO and its hydrophobicity, which favors its dispersion in PF. The decomposition of modified GO led to the formation of a carbon film, which served as a lubricant. In conclusion, the synergistic effect of GO and liquid crystal lowered down the friction and enhanced the wear resistance of composite samples.

Figure 15 shows the effect of c-PHDT/GO content on the density and hardness of composites. As we can see, with increasing content of c-PHDT/GO, the sample hardness increased and then decreased. With c-PHDT/GO content to be $0.5 \%$, the sample hardness was maximized. Sample hardness was positively related to the deformation resistance and wear resistance, while the density was not affect by the c-PHDT/GO content.

\subsubsection{Effect on the DMA of Composites}

Figure 16, Figure 17 and Table 8 show the effect of c-PHDT/GO content on the DMA results of composites. As we can see, with the c-PHDT/GO content to be $0.75 \%$, the composite showed a storage modulus of 7514 MPa (28.4\% higher than pure PF sample), $6057 \mathrm{MPa}$ (20.5\% higher than pure PF sample) and $4360 \mathrm{MPa}$ (14.2\% higher than pure PF sample) at $50^{\circ} \mathrm{C}, 100^{\circ} \mathrm{C}$ and $150^{\circ} \mathrm{C}$ respectively. With the c-PHDT/GO content to be $0.5 \%$, the composite showed a storage modulus of $2555 \mathrm{MPa}\left(29.8 \%\right.$ higher than pure $\mathrm{PF}$ sample) at $200^{\circ} \mathrm{C}$. The results revealed that the rigidity of composite samples can be enhanced by involvement of c-PHDT/GO, which can be explained by the improved dispersion of GO in the composite and interfacial effect as a result of surface modification by liquid crystal polymer.

According to the temperature and loss factor curves, the loss factor peaks of GO/PF composites were broad and smooth, indicating that the glass transition regions of these samples were extended. With the c-PHDT/GO content to be $1.0 \%$, the $\mathrm{T}_{\mathrm{g}}$ of different samples were $234^{\circ} \mathrm{C}, 238.7^{\circ} \mathrm{C}, 236.9^{\circ} \mathrm{C}, 227.7^{\circ} \mathrm{C}$ and $224.6^{\circ} \mathrm{C}$ respectively, which are consistent with the pure PF sample. 


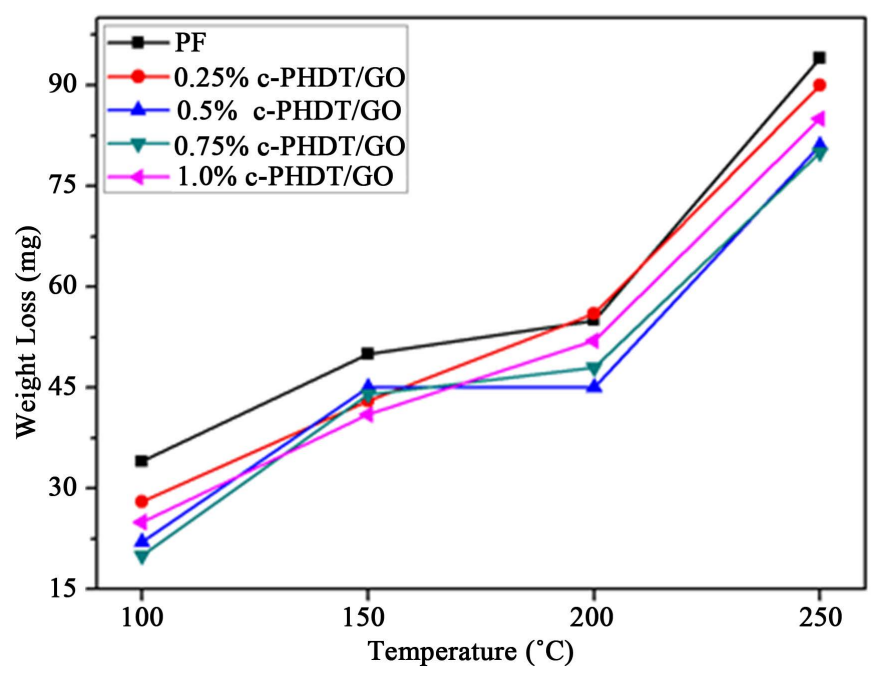

Figure 14. The effects of c-PHDT/GO contents on wear mass of PF composites.

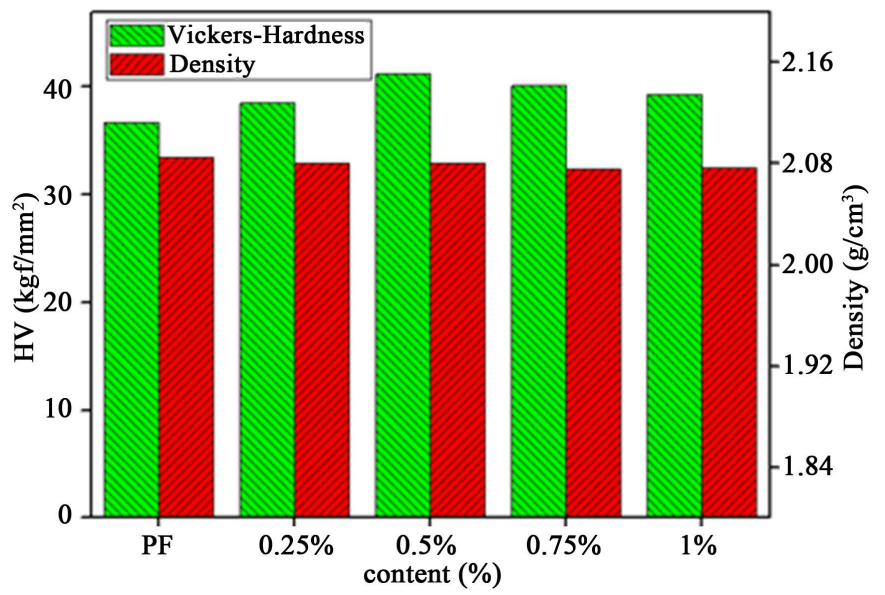

Figure 15. The effects of c-PHDT/GO contents on hardness and density of friction samples.

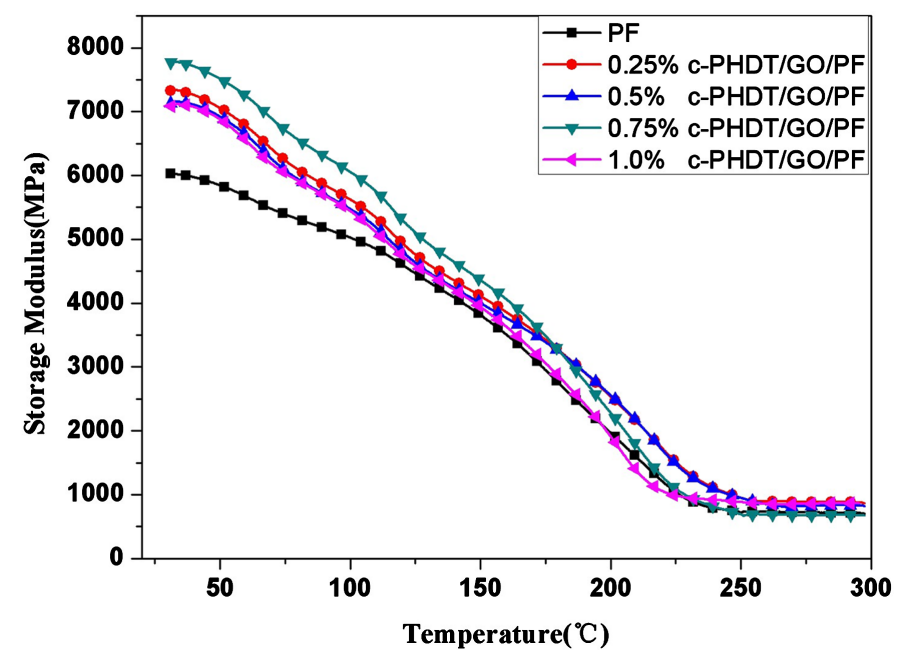

Figure 16. The effects of c-PHDT/GO contents on storage modulus of PF composites. 


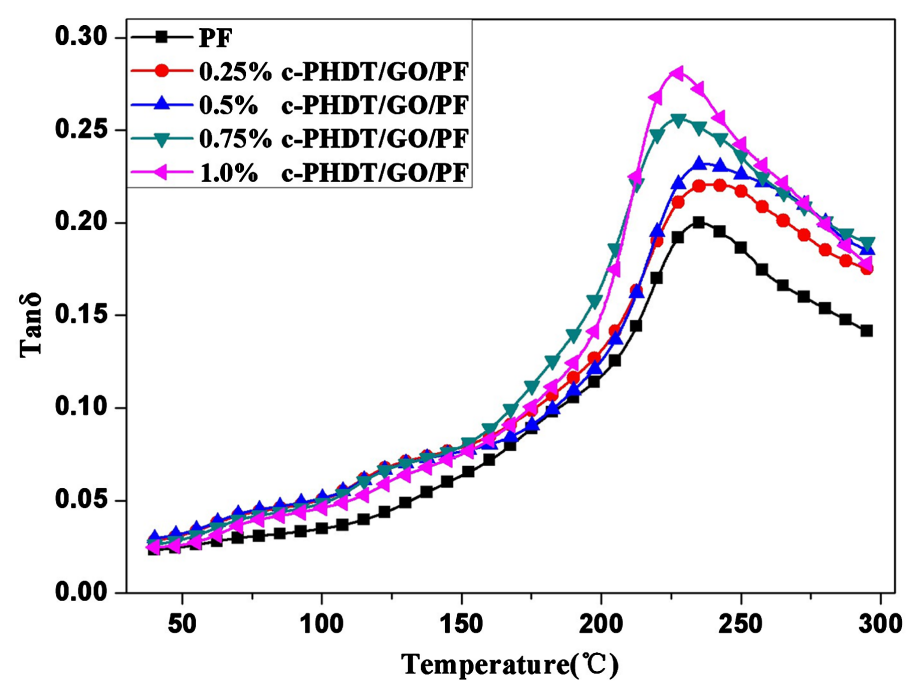

Figure 17. The effects of modified GO contents on Tan $\delta$ of PF composites.

Table 6. Effects of c-PHDT/GO contents on the mechanical properties of PF composites.

\begin{tabular}{cccc}
\hline c-PHDT/GO (\%) & Impact strength $\left(\mathrm{KJ} / \mathrm{m}^{2}\right)$ & Flexural modulus $(\mathrm{G} \mathrm{Pa})$ & Flexural strength $(\mathrm{M} \mathrm{Pa})$ \\
\hline 0 & 1.63 & 8.61 & 41.55 \\
0.25 & 2.08 & 9.82 & 50.33 \\
0.5 & 2.30 & 9.9 & 53.87 \\
0.75 & 2.31 & 10.16 & 54.40 \\
1.0 & 2.12 & 10.07 & 51.46 \\
\hline
\end{tabular}

Table 7. The effects of c-PHDT/GO contents on wear property of PF composites.

\begin{tabular}{|c|c|c|c|c|c|c|}
\hline Samples & $\mathrm{M}_{100}(\mathrm{mg})$ & $\mathrm{M}_{150}(\mathrm{mg})$ & $\mathrm{M}_{200}(\mathrm{mg})$ & $\mathrm{M}_{250}(\mathrm{mg})$ & $\mathrm{M}_{\mathrm{R}}(\mathrm{mg})$ & $\mathrm{M}_{\mathrm{S}}(\mathrm{mg})$ \\
\hline 0 & 34 & 50 & 55 & 94 & 42 & 275 \\
\hline 0.25 & 28 & 43 & 56 & 90 & 35 & 252 \\
\hline 0.5 & 22 & 45 & 45 & 81 & 34 & 227 \\
\hline 0.75 & 20 & 44 & 48 & 80 & 34 & 226 \\
\hline 1.0 & 25 & 41 & 41 & 85 & 35 & 238 \\
\hline
\end{tabular}

Table 8. Effects of c-PHDT/GO contents on dynamical mechanical properties of PF composites.

\begin{tabular}{cccccc}
\hline Samples & $\mathrm{E}_{50}^{\prime}(\mathrm{MPa})$ & $\mathrm{E}^{\prime}{ }_{100}(\mathrm{MPa})$ & $\mathrm{E}_{150}^{\prime}(\mathrm{MPa})$ & $\mathrm{E}_{200}^{\prime}(\mathrm{MPa})$ & $\mathrm{Tg}\left({ }^{\circ} \mathrm{C}\right)$ \\
\hline 0 & 5850 & 5027 & 3818 & 1968 & 234 \\
0.25 & 7054 & 5652 & 4109 & 2538 & 228 \\
0.5 & 6920 & 5477 & 3999 & 2555 & 236 \\
0.75 & 7514 & 6057 & 4360 & 2281 & 227 \\
1.0 & 6879 & 5445 & 3939 & 1911 & 224 \\
\hline
\end{tabular}

\section{Conclusions}

- For the composite based on synthetic PHDT modified graphene oxide (c-PHDT/GO), red shift was observed in the Raman spectrum, indicating the resence of $\pi-\pi^{*}$ conjuga-tion between c-PHDT and GO. The thermo- 
gravimetric analysis results revealed that the initial temperature of thermal decomposition for c-PHDT/GO was $357^{\circ} \mathrm{C}$ and the carbon yield at $\mathrm{T}=700^{\circ} \mathrm{C}$ was $22.9 \%$, indicating that the thermal stability of GO was significantly enhanced. Characterization by Polarizing Optical Microscope showed that the c-PHDT/GO was a liquid crystal in a way as birefraction phenomenon was observed, in spite that it was attenuated as compared to pure PHDT.

- The GO modification by PHDT which was liquid crystalline polymer had a significant positive effect on the mechanical performance and DMA of PF composites. The impact strength of c-PHDT/GO/PF composite increased by $27.6 \%$ and $11.1 \%$, the bending strength increased by $11.8 \%$ and $7.6 \%$, the initial storage modulus increased by $16.2 \%$ and $4.2 \%$ and the mass loss due to wear decreased by $12.7 \%$ and $8.8 \%$, as compared to $\mathrm{GO} / \mathrm{PF}$ and p-PHDT/GO/PF, respectively. These results revealed that the surface modification of GO by poly(hexanedithiol) achieved synergistic reinforcement.

- The content of c-PHDT/GO was proved to be directly related to the mechanical performance and DMA of PF composites. With c-PHDT/GO content to be $0.75 \%$, the impact strength, bending modulus and bending strength increased from $1.63 \mathrm{~kJ} / \mathrm{m}^{2}, 8.61 \mathrm{GPa}$ and $41.55 \mathrm{MPa}$ to $2.31 \mathrm{~kJ} / \mathrm{m}^{2}, 10.16 \mathrm{GPa}$ and $54.40 \mathrm{MPa}$ respectively, as compared to the pure PF samples. Moreover, the initial storage modulus increased by $28.4 \%$, while the wear mass loss decreased by $17.8 \%$.

\section{Acknowledgements}

The authors would like to acknowledge the National Natural Science Foundation of China (Grant No.: 51163003, 51263005, 21264005), Guangxi Natural Science Foundation of China (Grant No.: 2013GXNSFDA 019008).

\section{References}

[1] Novoselov, K.S., Geim, A.K., Morozov, S.V., Jiang, D., Zhang, Y., Dubonos, S.V., et al. (2004) Electric Field Effect in Atomically Thin Carbon Films. Science, 306, 666-669. http://dx.doi.org/10.1126/science.1102896

[2] Balandin, A.A., Suchismita, G., Bao, W., Calizo, I., Teweldebrhan, D., Miao, F. and Lau, C.N. (2008) Superior Thermal Conductivity of Single-Layer Graphene. Nano Letters, 8, 902-907. http://dx.doi.org/10.1021/nl0731872

[3] Stoller, M.D., Park, S., Zhu, Y., An, J. and Ruoff, R.S. (2008) Graphene-Based Ultracapacitors. Nano Letters, 8, 34983502. http://dx.doi.org/10.1021/nl802558y

[4] Lee, C., Li, Q.Y., Kalb, W., Liu, X.Z., Berge, H., Robert, W.C. and Hone, J. (2010) Frictional Characteristics of Atomically Thin Sheets. Science, 328, 76-80. http://dx.doi.org/10.1126/science.1184167

[5] Lee, C., Wei, X., Li, Q., Carpick, R., Kysar, J.W. and Hone, J. (2009) Elastic and Frictional Properties of Graphene. Phys. Status Solidi B, 246, 2562-2567. http://dx.doi.org/10.1002/pssb.200982329

[6] Lee, C., Wei, X., Kysar, J.W. and Hone, J. (2008) Measurement of the Elastic Properties and Intrinsic Strength of Monolayer Graphene. Science, 321, 385-388. http://dx.doi.org/10.1126/science.1157996

[7] Liang, J., Wang, Y., Huang, Y., Ma, Y., Liu, Z., Cai, J., et al. (2009) Electromagnetic Interference Shielding of Graphene/Epoxy Composites. Carbon, 47, 922-925. http://dx.doi.org/10.1016/j.carbon.2008.12.038

[8] Ramanathan, T., Abdala, A.A., Stankovich, S., Dikin, D.A., Herrera-Alonso, M., Piner, R.D., et al. (2008) Functionalized Graphene Sheets for Polymer Nanocomposites. Nature Nanotechnology, 3, 327-331. http://dx.doi.org/10.1038/nnano.2008.96

[9] Stankovich, S., Piner, R.D., Nguyen, S.B.T. and Ruoff, R.S. (2006) Synthesis and Exfoliation of Isocyanate-Treated Graphene Oxide Nanoplatelets. Carbon, 44, 3342-3347. http://dx.doi.org/10.1016/j.carbon.2006.06.004

[10] Verdejo, R., Barroso-Bujans, F., Rodriguez-Perez, M.A., Saja, J.A. and Lopez-Manchado, M.A. (2008) Functionalized Graphene Sheet Filled Silicone Foam Nanocomposites. Journal of Materials Chemistry, 18, 2221-2226. http://dx.doi.org/10.1039/b718289a

[11] Ou, J.F., Wang, J.Q., Liu, S., Mu, B., Ren, J.F., Wang, H.G. and Yang, S.R. (2010) Tribology Study of Reduced Graphene Oxide Sheets on Silicon Substrate Synthesized via Covalent Assembly. Langmuir, 26, 15830-15836. http://dx.doi.org/10.1021/la102862d

[12] Fang, M., Wang, K., Lu, H., Yang, Y. and Nutt, S. (2009) Covalent Polymer Functionalization of Graphene Nanosheets and Mechanical Properties of Composites. Journal of Materials Chemistry, 19, 7098-7105. http://dx.doi.org/10.1039/b908220d

[13] Lu, P., Feng, Y.Y., Zhang, X.Q., Li, Y. and Feng, W. (2010) Recent Progresses in Application of Functionalized Gra- 
phene Sheets. Science China Technological Sciences, 53, 2311-2319. http://dx.doi.org/10.1007/s11431-010-4050-0

[14] Lei, Y., Wu, Q. and Lian, K. (2006) Cure Kinetics of Aqueous Phenol-Formaldehyde Resins Used for Oriented Strandboard Manufacturing: Analytical Technique. Journal of Applied Polymer Science, 100, 1642-1650. http://dx.doi.org/10.1002/app.23756

[15] Jin, Y.Q., Cheng, X.S. and Zheng, Z.B. (2010) Preparation and Characterization of Phenol-Formaldehyde Adhesives Modified with Enzymatic Hydrolysis Lignin. Bioresource Technology, 101, 2046-2048. http://dx.doi.org/10.1016/j.biortech.2009.09.085

[16] Lee, W.J., Chang, K.C. and Tseng, I.M. (2012) Properties of Phenol-Formaldehyde Resins Prepared from Phenol-Liquefied Lignin. Journal of Applied Polymer Science, 124, 4782-4788.

[17] Shen, H.B. and Nutt, S.R. (2003) Mechanical Characterization of Short Fiber Reinforced Phenolic Foam. Composites Part A: Applied Science and Manufacturing, 34, 899-906. http://dx.doi.org/10.1016/S1359-835X(03)00136-2

[18] Kiss, G. (1987) In Situ Composites: Blends of Isotropic Polymers and Thermotropic Liquid Crystalline Polymers. Polymer Engineering \& Science, 27, 410-423. http://dx.doi.org/10.1002/pen.760270606

[19] Champagne, M.F., Dumoulin, M.M., Utrack, L.A. and Szabo, J.P. (1996) Generation of Fibrillar Morphology in Blends of Block Copolyetheresteramide and Liquid Crystal Polyester. Polymer Engineering \& Science, 36, 1636-1646. http://dx.doi.org/10.1002/pen.10560

[20] Qin, Y., Brydon, D.L., Mather, R.R. and Wardman, R.H. (1993) Fibres from Polypropylene and Liquid Crystal Polymer (LCP) Blends: 1. Effect of LCP Concentration. Polymer, 34, 1196-1201. http://dx.doi.org/10.1016/0032-3861(93)90772-3

[21] Souza, J.P.D. and Baird, D.G. (1996) In Situ Composites Based on Blends of a Poly(ether imide) and Thermotropic Liquid Crystalline Polymers under Injection Moulding Conditions. Polymer, 37, 1985-1997. http://dx.doi.org/10.1016/0032-3861(96)87317-4

[22] Wei, C., Zeng, M., Xiong, X.M. and Zhang, F.A. (2010) Thermal and Frictional Properties of Modified Sisal Fibre/Phenolic Resin Composites. Plastics, Rubber and Composites, 39, 61-66. http://dx.doi.org/10.1179/174328910X12608851832452

[23] Lu, S.R., Jiang, Y.M. and Wei, C. (2009) Preparation and Characterization of EP/SiO ${ }_{2}$ Hybrid Materials Containing PEG Flexible Chain. Journal of Materials Science, 44, 4047-4055. http://dx.doi.org/10.1007/s10853-009-3584-7

[24] Mu, Q.H., Wei, C. and Feng, S.Y. (2009) Studies on Mechanical Properties of Sisal Fiber/Phenol Formaldehyde Resin In-Situ Composites. Polymer Composites, 30, 131-137. http://dx.doi.org/10.1002/pc.20529

[25] Yu, X.B., Wei, C., Xu, D., Lu, C.H., Yu, J.H. and Lu, S.R. (2007) Wear and Mechanical Properties of Reactive Thermotropic Liquid Crystalline Polymer/Unsaturated Polyester/Glass Fiber Hybrid Composites. Journal of Applied Polymer Science, 103, 3899-3906. http://dx.doi.org/10.1002/app.25593

[26] Verdejo, R., Barroso-Bujans, F. and Rodriguez-Perez, M.A. (2008) Functionalized Graphene Sheet Filled Silicone Foam Nanocomposites. Journal of Materials Chemistry, 18, 2221-2226. http://dx.doi.org/10.1039/b718289a

[27] Schniepp, H.C., Li, J.L., McAllister, M.J., Sai, H., Herrera Alonso, M., Adamson, D.H., et al. (2006) Functionalized Single Graphene Sheets Derived from Splitting Graphite Oxide. The Journal of Physical Chemistry B, 110, 8535-8539. http://dx.doi.org/10.1021/jp060936f

[28] Tan, S.T., Zhang, H.L. and Wang, X.Y. (1998) Chinese Journal of Polymer Science, 2, 167-171.

[29] Kumar, N.A., Choi, H.J., Shin, Y.R., Chang, D.W., Dai, L.M. and Baek, J.B. (2012) Polyaniline-Grafted Reduced Graphene Oxide for Efficient Electrochemical Supercapacitors. ACS Nano, 6, 1715-1723. 